\title{
O ÔNUS DA PROVA NA DISPENSA DISCRIMINATÓRIA EM RAZÃO DO GÊNERO
}

\section{THE BURDEN OF PROOF IN DISCRIMINATORY DISPENSATION FOR GENDER}

Heron Gordilho ${ }^{1}$

Eduardo Milléo Baracat ${ }^{2}$

Isabella Calabrese Simão ${ }^{3}$

\section{RESUMO}

Há anos a luta pela igualdade da mulher com relação ao homem vem sendo travada. Em que pese a desigualdade entre homens e mulheres venha diminuindo, ainda é muito acentuada, principalmente no âmbito do contrato de trabalho. Assim, a discriminação da mulher durante a relação empregatícia pode ser verificada em diversos momentos: na contratação, durante a execução do contrato de trabalho, e, mesmo após a rescisão contratual. A discriminação da mulher na rescisão contratual, contudo, merece especial atenção, mormente ante a dificuldade probatória. O presente trabalho, portanto, investiga o ônus da prova nos processos em que se discute a dispensa discriminatória em razão do gênero, como, ainda, quais provas estariam aptas para essa finalidade.

Palavras-chave: Discriminação. Mulher. Ônus da prova.

\section{ABSTRACT}

For years the struggle for women's equality with men has been fought. Although women achieve a high degree of equality, they are still confronted with some discrimination, especially within the labor market. Discrimination against women's work is present at

1 Professor visitante na École des Hautes Études en Science Sociales (EHESS/Paris/FR). Pós-Doutor pela Pace University Law School, Nova York. Porfessor colaborador do Master Derecha Animal \& Siciedad ( Universidad Autonoma de Barcelona/ESP). Doutor em Direito na Universidade Federal de Pernambuco. Professor do corpo permanente do PPGD/UFBA. Professor do Corpo Permanente do PPGD/UCSAL.

2 Doutor em Direito das Relações Sociais pela Universidade Federal do Paraná (2002). Mestre em Direito Privado pela Universidade Federal do Paraná (1995). Diplôme Supérieur de 1’Université - Droit du Travail \& Sécurité Sociale pela Université Panthéon-Assas/Paris II (1998). Juiz Titular da 9a Vara do Trabalho de Curitiba. Professor Permanente do Programa de Mestrado em Direito Empresarial e Cidadania do UNICURITIBA. Realizou estágio Pós-Doutoral na Universidade de Coimbra (2016-2017).

3 Advogada, graduada em Direito pelo Centro Universitário Curitiba, pós graduada em Direito e Processo do Trabalho pela EMATRA, mestranda em Direito Empresarial e Cidadania pelo Centro Universitário Curitiba. 
different stages, either at the time of hiring, during the performance of the employment contract or at the time of dismissal. However, dealing more specifically with the discrimination of women in dismissal, another very important point comes into question, which is the proof that the dismissal occurred because of being a woman. Who should prove such a fact? Who has better conditions for this? How can this test be performed?

Keywords: Discrimination. Woman. Burden of proof.

\section{INTRODUÇÃO}

A igualdade pode ser anallisada a partir de diversas dimensões, conforme observa Antonio Enrique Pérez Luño em sua clássica obra Dimensiones de la igualdad. ${ }^{4}$

A igualdade, desse modo, pode ser analisada sobre um perspectiva valorativa, como referencial axiológico de interpretação da normal. A igualdade possui, ainda, uma dimensão principiológica que permite a concreção valorativa à situação conflituosa. Sob o viés principiológico, a igualdade possui dois sentidos essenciais: formal e material. A igualdade formal é representada pela igualdade de todos perante a lei, enquanto a igualdade material purgna pela superação das desigualdades reais de indivíduos ou grupos, por meio de ações externas que objetivam compensá-las.

A igualdade material, portanto, possui um inequívoco sentido de justiça.

Outra certeza que podemos ter é com relação a desiguladade existente entre homens e mulher no mercado de trabalho brasileiro, que ainda é bastante expressiva. Essa desiguldade tem alguns determinantes, que na maioria das vezes são elementos histórico culturais em razão do gênero.

Isso fica mais evidente quando analisamos os dados estatísticos entre homens e mulheres, mostrando que, embora as mulheres sejam tão qualificadas, ou as vezes até mais, ainda há muita discrepância nos salários, na contratação, na promoção e na dispensa entre e empregados e empregadas. Ou seja, cada vez mais, as trabalhadores são menos contratadas em que os trabalhadores, ou menos promovidas, ou, ainda, dispensadas em maior número.

Por outro lado, essa realidade discriminatória, na maioria das vezes, fica impune, pela dificuldade que se tem de prová-la, sobretudo, como causa da dispensa imotivada da empregada. Assim, a delimitação temática da presente pesquisa centra-se no ônus da prova

\footnotetext{
${ }^{4}$ LUÑO, Antonio Enrique Pérez. Dimensiones de la igualdad. Madri: Dykinson, 2007.
} 
quando se discute, no processo do trabalho, dispensa discriminatória em razão do gênero, sobretudo ante a teoria da distribuição dinâmica do ônus da prova, prevista no art. $818, \S 1^{\circ}$, da CLT, com redação dada pela Lei n ${ }^{\circ} 13.467 / 2017$.

Busca-se, dessa maneira, com a presente pesquisa enfrentar a seguinte problemática: em que medida a teoria da distribuição dinâmica do ônus da prova, prevista no art. $818, \S 1^{\circ}$, da CLT, com redação dada pela Lei $n^{\circ} 13.467 / 2017$ pode ser eficaz para se comprovar a discriminação em relação ao gênero nas hipóteses de dispensa sem justa causa da trabalhadora?

\section{IGUALDADE E DISCRIMINAÇÃO DA MULHER NA RELAÇÃO DE EMPREGO}

\subsection{PRINCÍPIO DA IGUALDADE}

A igualdade é uma condição da liberdade, é impossivel falar de igualdade sem falar em liberdade, e vice versa, assim, a igualdade deve ser entendida no seu conceito mais amplo, como o reconhecimento público das diferenças e da liberdade, como a criação de espaços políticos adequadados a elas.

Em que pese as pessoas sejam diferentes umas das outras, a igualdade enquanto direito de liberdade garante que todos são igualmente livres para exercerem e expressarem suas diferenças, seja qual for a sua natureza. Dessa forma, não importa qual sejam as diferenças, todos são iguais como seres humanos. (GRUBBA e CADEMARTORI, 2012, p.42-43)

Como explica Joaquim Barbosa Gomes (2001), a noção de igualdade, como categoria jurídica de primeira grandeza, nasceu como princípio jurídico absoluto, sendo que a partir das experiencias revolucionárias dos Estados Unidos e da França, o conceito de igualdade perante a lei, onde a principal premissa é de que a lei deve ser igual para todos, sem qualquer distição ou

privilegio, com aplicação neutra em situações jurídicas concretas e sobre conflitos interindividuais.

Resta claro que a igualdade possue uma repercussão tanto social, como também, política, econômica e jurídica, sendo uma valor guia da ética política, social e jurídica.

Sendo assim, a Constituição Federal de 1988, no caput do seu artigo $5^{\circ}$, adotou o princípio da igualdade de direitos, garantindo a todos os cidadões direitos iguais perante a lei. No entanto esse principio opera em dois planos diferentes: igualdade formal e igualdade material. 


\subsubsection{IGUALDADE FORMAL E IGUALDADE MATERIAL}

A igualdade formal refere-se a necessidade de edição de leis, atos normativos e medidas provisórias, as quais garantam a igualdade a todas as pessoas, identificada como um requisito legal político, sintetizado no principio da igualdade perante a lei. Ou seja, a igualdade formal garante a existência de previsões legais dentro do ordenamento jurídico que impeça a criação de tratamentos diferenciados a pessoas que estão em situações identicas. (MORAES, 1999, p. 62)

Implica no reconhecimento do mesmo estatuto jurídico a todos os cidadões, garantindo a paridade de tratamento na legislação e na aplicação do direio. (LEIBHOLZ, 1959, p. 16)

No entanto, a simples previsão legal de tratamento isonômico, não garante a igualdade real, embora seja de extrema importancia a existência da previsão legal do princípio da igualdade, a realidade demonstra que, sozinha, é insuficiente para garatir a igualdade em direitos de fato entre os indivíduos.

Para que isso seja possível, é necessário delinear o princípio da igualdade em sentido material, assegurando essa igualdade concreta por meio da lei ou outras medidas, tratando igual o que é igual e desigual o que é desigual. (CANOTILHO, 2000, p. 416)

Destarte, é imprescidivél a concretização da igualdade nas relações sociais, sendo necessário a reavaliação deste princípio, mediante a diferenciação de igudalde meramente formal e igualdade material.

Alice Monteiro de Barros (2000, p.39), explica que o princípio da igualdade nos sistemas constitucionais de base liberal-democrático possui duas caracteristicas: de princípio formal de legalidade, mas também, de regra material de não discriminação, o qual vincula o legislador, tanto a forma externa da lei, quanto ao seu conteúdo.

Não obstante, o princípio da igualdade, em termos gerais, conduz a necessidade de integração das tensões subjacentes os seus aspectos formais/legais e materiais/factuais. (ALEXY, 2015, p. 403)

Joaquim Barbosa (2001, p. 4) ensina que, a igualdade material, que longe de se apegar ao formalismo e a abstratação da igualdade formal, recomenda o caminho inverso, devendo levar em conta as desigualdades concretas que existem na sociedade, sendo que as situações desiguais, devem ser tratadas de acordo com a sua desigualdade, afim de evitar o aprofundamento e a perpetuação da desigualdade que vem sendo engendrada pela própria sociedade. A igualdade materia deve ser a busca pela real igualdade entre os indivíduos, a partir do reconhecimento da existência de diferenças e desigualdades, as quais são merecedoras de proteção e tratamento especial. 
Leciona Boaventura de Sousa Santos (2003, p.56):

"Temos o direito de ser iguais quando a nossa diferença nos inferioriza; e temos o direito de ser diferentes quando a nossa igualdade nos descaracteriza. Daí a necessidade de uma igualdade que reconheça as diferenças e de uma diferença que não produza, alimente ou reproduza as desigualdades."

Dessa forma, almeja-se encontrar um ponto de equilibrio, onde haja um tratamento igualitário, respeitando as diferenças dos indivíduos.

Contudo, diversos são so motivos que levam a desigualdade, a diversidade de valores, interesses, crenças, sexo e etnias no espaço social e político levam a necessidade de implementação do princípio da igualdade (NEVES, 2006, p. 167). Assim, o pressuposto do Estado moderno é o de reconhecimento a diversidade afim de promover a igualdade.

Essa diversidade e consequentemente desigualdade torna-se ainda mais forte quando se trata de uma relação de emprego. Isso porque tal relação envolve subordinação, não estando as parte no mesmo degrau hierarquico.

Conforme explica Marcio Túlio Viana (2000, p. 322), o Direito do Trabalho precisa se esforçar mais ainda para reduzir a taxa de desigualdade e injustiça, sendo assim, o autor defende a necessidade de criar desigualdades para compensar outras desigualdades já existentes.

Na mesma esteira, Léa Silingowschi Calil (2007, p. 89), explica o dever de interpretar o princípio da igualdade diferente no que se refere o Direito do Trabalho, visando atender os comendados da relação de emprego, bem como a demanda no tratamento diferenciado dado as diversos tipos de trabalhadores, como as mulheres, negros, criança e adolescentes.

\subsection{DISCRIMINAÇÃO DA MULHER NA RELAÇÃO DE EMPREGO}

Um tema muito recorrente e muito tratado no mundo é a discriminação da mulher no ambiênte de trabalho. Isso porque, ao longo da história, o papel da mulher, de um modo geral, tem sido ampliado, na busca pela igualdade e reconhecimento dentro do mercado do trabalho.

Atualmente a mulher exerce quase todas as profissões, incluives aquelas que durante anos foram exercidas exclusivamente por empregados do sexo masculino.

Ao longo dos anos, a imagem social da mulher que trabalha, que constui uma carreira passou a ser valorizada e admirada (SGARBIERI, 2006, p.386) 
Além da superação da segregação ocupacional, as mulheres vem conquistando cada vez mais espaços e reconhecimento dentro do mercado de trabalho. Além disso, diversas leis foram editadas visando garantir o direito ao acesso ao mercado de trabalho pelas mulheres, possibilitando a conciliação entre a vida familiar e profissional, afim de evitar a discriminação em razão do gênero.

A Constituição Federal de 1988 , no artigo $7^{\circ}, \mathrm{XX}$, trouxe uma previsão muito importante na luta contra a discriminação do trabalho da mulher, a Carta Magna, ao versar sobre a proteção do mercado de trabalho da mulher, mediante incentivo, tratou de forma indireta a não discriminação da mulher na relação de empregado, possibilitando a igualdade de direitos e oportunidades a homens e mulheres, através de incentivos dados por lei ordinária. (MARTINS, 2007, p. 593)

Já o inciso XXX do mesmo artigo da CF, proibe de forma expressa a diferença entre homens e mulheres, no que se refere a salário, função e critéro de admissão.

No entanto, será que essa "batalha" feminina por direitos iguais dentro do mercado de trabalho, pela igualdade de oportunidades e de salários chegou ao fim? Atualmente, ainda existe discriminação da mulher na contratação? Dentro da relação de emprego? No momento da promoção? No momento da estipulação de salários? E principalmente, na rescisão contratual?

Dados referentes a ascensão profissional das mulheres e o tratamento despendidos as mulheres no ambiênte de trabalho demonstram a forte existência de preconceito de gênero dentro do mercado de trabalho, o fenômeno conhecido como "teto de vidro" é muito presente dentro da relação de emprego envolvendo empregada do gênero feminino.

De acordo com o referido fenômeno, ainda que as mulheres consigam entrar no mercado de trabalho, principalmente no mundo corporativo, constatam-se a presença de diversos mecanismos amplamente discriminaórios, em especial a dificuldade na acensão da mulher a posições hierárquicas mais elevadas dentro de uma empresa (STEIL, 1997, p.62-69)

Um levantamento realizado pela consultoria Grant Thornto destaca que, no Brasil, apenas 3\% dos cargos presidenciais das empresas são ocupados por mulheres e que, na média mundial, apenas 9\% das empresas tem mulheres nos cargos de presidenciais.

Tais dado demonstram a dificuldade feminina de ascenção de posições hierárquicas, restando uma parcela muito expressiva de mulheres que permanecem exercendo trabalhos precários, de baixa remuneração e produtividade. (LEITE E SALA, 2014, p.87)

Tal discriminação se torna ainda mais evidente quando analisados os números de escolaridade entre homens e mulheres. De acordo com o RAIS (Relação Anual de Informações Sociais), a maioria das mulheres possuem escolaridade superior a dos homens, principalmente a 
nivel de ensino superior e pós graduação, contudo, ao analisar os salários entre tais empregados com esolaridade superior, o salário médio feminino é bem inferior ao masculino, $\mathrm{R} \$ 4.360,00$ $\begin{array}{llllllll}\text { contra } & \mathrm{R} \$ \mathrm{7.004,70} \text { (diploma de graduação); } & \mathrm{R} \$ & 5.991,20 & \text { contra } & \mathrm{R} \$\end{array}$ 8.594,00 (mestrado); $\mathrm{R} \$ 9.190,10$ contra $\mathrm{R} \$ 11.334,00$ (doutorado). Ou seja, dentro de um cenário de empregados com maior grau de escolaridade, a remuneração média feminina corresponde a apenas $62,2 \%$ da remuneração média masculidade, quando ambos possuem graduação completa; $69,7 \%$ se ambos possuirem mestrado; e $81 \%$ se ambos possuem diploma de doutorado.

Diante dos dados apresentados, resta evidente a acentuada discriminação de gênero entre profissionais que competem pelos melhores postos de trabalho, tendo que, as mulheres enfrentarem barreiras invisíveis ("teto de vidro"), e consequentemente, terem muita dficuldade na hora de alcançar posições de destaque e maior produtividade. (PRONI e LEONE, 2003, p.5)

Outra ponto que contribui para a discriminação da mulher no mercado de trabalho, está relacionada a dupla jornada e a necessidade de conciliação da vida profissional e a vida pessoal.

Muitos empregadores dão preferência no momento da contratação a empregados do gênero masculino, ou até mesmo, só contratam empregados homens, por acreditarem que a possibilidade da empregada mulher engravidar torna aquele contrato de trabalho muito oneroso para a empresa, posto que terá que arcar com as questões de proteção da maternidade.

Nesta matéria que diversas situações de discriminação direita e indireta contra a mulher são observadas. Isso porque todos sabemos que empregadas são frequentemente dispensadas somente pelo fato de estarem grávidas, ainda que haja tutela legal nessas situações, ou então que deixaram de serem promovidas por tal motivo, ou ainda sofrem pressões, principalmente por meio de sanções disciplinares ocultas como mudança de tratamento, mudança de tarefas mais pesadas, dentre outras, afim de fazer com que a empregada chegue a tal situação que se torne impossível a continuação daquela relação de emprego. (RAMALHO, p. 242)

Assim, em que pese a proteção legal existente e as ações positivas, as quais visam proteger o trabalho da mulher, bem como garantir igualdade de direitos em relação ao homens dentro do mercado de trabalho, resta claro que a discriminação e o preconceito no que se refere a mulher dentro de uma relação de emprego é ainda muito presente na sociedade. 


\section{O ÔNUS DA PROVA NA DISPENSA DISCRIMINATÓRIA EM RAZÃO DO GÊNERO}

\subsection{O ÔNUS DA PROVA NO PROCESSO DO TRABALHO: EVOLUÇÃO}

Dentro de qualquer processo, a prova é, se não o mais importante, certamente um dos pontos mais importantes. Carnelutti dizia que "a prova é o coração do processo".

Isso porque, além do fato de que é pela prova produzida que o juiz decide o processo, ainda, o ônus da prova assumi um papel decisivo quando as provas produzidas deixam margens a dúvidas. Assim, não tendo o julgador plena conviçção dos fatos, é necesário estabelecer um critério sucessivo para a solução do conflito em questão, sendo esse critério a distribuição do ônus da prova. (JAKUTIS, 2017, p. 162)

No que se refere ao processo do trabalho, essa questão do ônus da prova é ainda mais delicada, visto que se refere a controvérsia envolvendo partes muito distintas, entre as quais há uma enorme disparidade de forças econômicas.

Aliado a isso, outra grande dificuldade encontrada no processo do trabalho em relação ao ônus da prova, se dá pelo fato de que a regra da CLT era considerada insatisfatória, já que atribuía, de forma simplista, que a prova das alegações incumbia à parte que as fizesse.

Atraia-se, em decorrência, a aplicação do art. 333 do CPC/1973 que adotava a teoria estática de distribuição do ônus da prova, de forma que cada litigante já tinha conhecimento, quando ingressava em juízo, de qual ônus lhe incumbia em relação à matéria probatória. No entanto, considerando tão-somente essa teoria, não se vislumbrava qualquer elemento que permitisse "uma otimização da produção da prova em situações em que uma das partes teria maior facilidade de obter a prova" (BARACAT, 2016).

Assim, embora de grande utilidade, a teoria estática não auxilia em casos em que o “desequilíbrio da relação jurídica havida entre as partes - especificamente durante o vínculo empregatício - é tão grande que impacta diretamente no processo, tornando extremamente difícil ou impossível o exercício do direito à prova", a partir dos critérios previstos no art. 333 do CPC/1973 (BARACAT, 2016).

Para dar conta dessa dificuldade e evitar situações de inequívoca injustiça, passou-se a adotar a técnica da inversão do ônus da prova, "a partir das máximas de experiência e da garantia constitucional do contraditório e da ampla defesa", permitindo que "a parte hipossuficiente (aquela desprovida de condições técnicas de provar um fato que poderia mais facilmente ser provado ppela outra parte)", obtivesse a justa prestação jurisdicional (BARACAT, 2016). 
Exemplo interessante da adoção da técnica da inversão do ônus da prova é o da Súmula 338, III, do TST, "segundo o qual considera-se normal que os registros de ponto demonstrem horários variáveis de entrada e saída, e por extraordinário, que esses mesmos registros espelhem horários invariáveis", de modo que se presumem inválidos os cartões-ponto que apresentam horários de entrada e saída uniformes, invertendo-se o ônus da prova, que passa a ser do empregador.

Há hipóteses de discriminação no âmbito de relação empregatícia, em especial no tocante ao gênero e a cor, que a inversão do ônus da prova também é insatisfatória, pois poderia gerar também situação de injustiça.

Ante a essa dificuldade, passou a admitir a distribuição do ônus da prova, de acordo com a teoria dinâmica, no sentido de que a prova incumbe ao litigante com melhores condições de produzi-la, que resultou incorporada pelo $\mathrm{CPC} / 2015$, no art. $373, \S 1^{\circ}$.

A Lei 13.476/2017, que estabeleceu diversas alterações na CLT, seguiu a mesma diretriz, alterando a redação do art. 818 da CLT para estabelecer, como regra geral, a teoria estática, e, exceção, a teoria dinâmica.

\subsubsection{TEORIA DA DISTRIBUIÇÃO DINÂMICA DO ÔNUS DA PROVA E O PROCESSO DO TRABALHO}

Embora tem-se a convicção da possibilidade de aplicação do previsto no artigo $6^{\circ}$ do CDC, permitindo a inversão do ônus probatório, ao processo do trabalho, ainda assim, resta insuficiente para a solução de todas as questões envolvendo o encargo probatório das lides trabalhistas. (JAKUTIS, 2017, p.171)

Isso porque, muitas vezes no processo trabalhista, o problema começa já na fixação inicial do ônus da prova, posto que, tal processo é calcado no princípio protecionista, não é necessário sequer cogitar a inversão do ônus, porque o ônus desde o começa já deveria ser alocado com o empregador.

É nesse momento que se torna indiscutível a utilização da chamada teoria da distribuição dinâmica do ônus da prova, a qual consiste em retirar o peso do encargo probatório a quem se encontra em evidente dificildade de suporta-lo, transferindo-o a quem possui maior e melhores condições de produzir a prova essencial para a solução do conflito em questão.

Para tanto é necessário avaliar a compatibilidade da utilização do referido instituto, de acordo com as normas previsas na CLT. Entrementes, a partir do momento que a sua utilização torna a prova impossível a uma das partes, abre-se a possibilidade de utilização da teoria dinâmica 
do ônus da prova, buscando, assim, uma maneira mais justa para a distribuição dos encargos probatórios entre as partes.

Aliado a isso, sabendo-se que o processo tem como principal finalidade fazer valer, no caso concreto, o direito material, permitindo a entrega da adequada e justa prestação jurisdicional, e que a teoria da distribuição dinâmica do ônus da prova parte da premissa de que cabe a parte que está em melhores condições (independente de ser ela autor ou réu) a produção da prova, sendo que a sua utilização está apta para cumprir com tal ideal.

Então, através da utilização da teoria da distribuição dinâmica do ônus da prova, pode o juiz, de acordo com a análise dos fatos trazidos pelas partes, desonerar o empregado do encargo probatório excessivo para a comprovação dos fatos alegados na inicial, transferindo tal obrigação ao empregador, quando verificar que esse possui melhores condições de fazê-lo, de acordo com quem tem melhores condições de provar, visando a maior cooperação das partes no processo.

Certo é que uma pessoa física não tem as mesmas condições pocessuais de uma pessoa jurídica, posto que esta possui maiores recursos econômicos e pode ter maior influência política nas decisões do que aquela (MARTINS, 2018, p.449).

Ao analisarmos a produção de prova testemunhal, amplamente utilizada no processo do trabalho, um empregado tem muito mais dificuldade em convidar a testemunha para depor em juízo, uma vez que, essa muita vezes teme perder o emprego se faltar no serviço ou, ainda, por depor em processo judicial. Diferente é a situação do empregador que leva suas testemunhas, que normalmente são os próprios empregados da empresa.

Ressalta-se ainda que a empresa tem a posse dos documentos relativos ao contrato de trabalho do reclamante.

Diante dessa diferença de condições de produção de prova, em certos casos é impossível a não utilização da distribuição dinâmica do ônus da prova, contudo, não se aplica o in dubio pro operário em se tratando de prova.

Ao juiz não cabe a proteção da parte mais fraca, que é o empregado. O magistrado deve analisar as provas produzidas nos autos de forma imparcial, sob pena de tratar as partes de maneira desigual. (MARTINS, 2018, p. 451)

Contudo, cabe ao juiz tornar possível a prova de alguns fatos alegados pelo empregado mas que não podem ser provados por ele.

Visando tal situação o legislador da Reforma Trabalhista acrescentou ao artigo 818 da CLT, a possibilidade, com base no texto legal, do juiz atribuir o ônus da prova de modo diverso, desde que o faça atraves de decisão fundamentada, caso que deverá dar a parte a oportunidade de se desincumbir do ônus que lhe foi atribuído $\left(\S 1^{\circ}\right.$ do art.818 da CLT) 
Contudo a distribuição de forma diversa é uma faculdade de juiz e não uma obrigação, cabendo a ele decidir, sempre de forma fundamentada, a quem incumbe o ônus da prova, para que não haja surpresa da parte com a sentença, na qual o juiz diz que a parte não fez prova.

De acordo com o $\S 2^{\circ}$ do artigo 818 da CLT, a decisão da inversão do ônus da prova deve ser proferida antes da abertura da instrução processual, possibilitando a parte requerer o adiamente da audiência.

\section{O ÔNUS DA PROVA NA DISPENSA DISCRIMINATÓRIA EM RAZÃO DO SEXO}

Não é difícil imaginar que uma empregada que esteja diante de uma situação de discriminação tenha grandes dificuldades de provar tal fato. Devido a essa dificuldade, alguns países editaram uma legislação expressa e específica sobre referida situação, onde há a prévia inversão do ônus da prova, prevista na lei, para situações que envolvam casos de discriminação.

Por exemplo, na Itália, Vittorio Denti (1992, p. 13) ensina que, a legislação de 1991 inovou quanto a distribuição do ônus da prova em casos envolvendo discriminação da mulher no ambiente de trabalho. Segundo o autor, a nova legislação limitou a empregada a prova de um prima face case, ou seja, a ela cabe apenas apresentar os elementos de fato idôneos para alicerçar a presunção de existência da discriminação em razão do sexo, atribuíndo o ônus de provar que não houve comportamento discriminatório ao empregador.

Assim, em se tratando de casos que haja alegação de discriminação em razão do sexo, segundo as legais italianas, se verifica a inversão do ônus da prova, cabendo a trabalhadora, apenas alegar a situação, apresentando os fatos ocorridos, e ao empregador provar que não houve a discriminação, que tal situação não ocorreu em razão do gênero.

Já no Brasil, embora o debate doutrinário e jurisprudêncial sejam intenso no que se refere a essas situações, a legislação ainda é muito tímida.

Em que pese haja bastante julgados, com discussões muito interessantes sobre o ônus da prova em caso de discriminação, e em alguns casos, determinando a redistribuição desse ônus, no que se refere a legislação, ainda não houve nenhuma alteração expressa e específica, prevendo a inversão do ônus da prova em casos de discriminação, como é o caso da Itália, por exemplo.

No entanto, certo é que a edição da súmula 443 do TST é considerado um marco no que tange a situações que envolvam discriminação do empregado.

Inicialmente a referida súmula estabelecia que havia a presunção discriminação na dispensa de empregado portador do vírus HIV, considerando a dispensa discriminatória e determinando a reintegração do empregado. 
Posteriormente, o TST acrescentou a súmula 443 a presunção de dispensa discriminatória com imediata reintegração do empregado portador do vírus HIV ou de outra doença grave que cause estigma ou preconceito.

Ao que tudo indica, o TST utilizou-se de precedentes da jurisprudência estatunidense, a qual possui previsões próximas ao da súmula supra, aplicáveis aos casos de discriminação por disparate treatment, ou seja, casos em que permite ao trabalhador apesar apresentar os fatos ocorridos e ao empregador suportar o ônus probatório, sob pena de conderar-se que houve a dispensa discriminatória. (JAKUTIS, 2017, p. 177)

Ocorre que o TST não deixou claro se essa postura poderia ser aplicada, também, para outros casos de discriminação, como por exemplo, a discriminação em razão do gênero, da raça, entre outras.

\subsection{DISCRIMINAÇÃO: PROBABILIDADE E ESTATÍSTICA}

Quando o assunto é ônus da prova e discriminação é impossível não falarmos em reflexões numéricas e termos matemáticos.

Isso porque a partir das décadas de 60/70, diversos estudos foram realizados por juristas e matemáticos ingleses abrangendo conceitos estatísticos e o direito processual, principalmente no que se refere a questão da prova.

Tais estudos demonstraram que, tendo em vista que o julgador é um terceiro que não presenciou os fatos discutidos no processo, em última análise o seu julgamento está lastreado a questão da probabilidade. Ou seja, um juiz jamais terá $100 \%$ de certeza que algo que não presenciou, podendo, ao máximo, chegar a uma conclusão lógica sobre a probabilidade do fato ter ou não acontecido.

Assim, diante de tal premissa, certo é que a probabilidade e a estatística (conceitos estudados na matemática), podem oferecer subsídios no que se refere a questão do ônus da prova, bem como da decisão e do exame das provas produzidas pelas partes. (JAKUTIS, 2017, p.198)

Então, cada vez mais a utilização da prova estatísticas no que se refere a situações de discriminação passaram a fazer parte da rotina dos processos, sendo, a prova estatística, reconhecida pela jurisprudência, principalmente americana, como uma meio de prova científica e valida dentro do processo trabalhista.

Assim, diante de casos de disparate impact, apresentando fatores de discriminação na relação de emprego, principalmente na contratação, promoção e rescisão contratual, demonstrativos estatísticos por parte do empregado de que houve a discriminação, são suficientes 
para cumprir com o ônus de um prima facie case, sendo então de responsabilidade do empregador a apresentação de uma justificativa razoável de que não houve discriminação na situação relatada. (JAKUTIS, 2017, p. 199)

Diante de inúmeros casos modelos americanos em que a matemática e da estatística foram utilizadas como meio de prova em processos envolvendo questões de discriminação, certo é que no Brasil, tais conceitos não são adotados com frequência no que tange a prova de discriminação no processo do trabalho.

No entanto, fato é que não se falar em solução de um processo trabalhista sem a utilização da matemática e da estatística, e por isso juristas do universo trabalhista não são completamente avessos ao recursos da matemática, havendo momento em que tais recursos matemáticos são ferramentas indispensáveis e que facilitam muito a tarefa do especialista em direito. (JUKUTIS, 2017, p. 210)

Assim, não se discute a compatibilidade da matemática, não só com o processo trabalhista, mas também com o processo em geral. Diante dessa compatibilidade e da facilidade que a utilização de conceitos matemáticos e estatísticos podem oferecer, possibilitando uma vasta gama de recursos que podem, efetivamente, dar mais segurança as decisões, tornando-as mais justas e adequadas, qual seria o motivo para a não utilização desse conhecimento?

Sendo assim, em se tratando de ônus da prova em dispensa discriminatória em razão do gênero, algumas aspactos devem ser analisados e levados em conta dentro do processo trabalhista e na distribuição desse encargo probatório.

\section{CONCLUSÃO}

Nos últimos anos aumento a participação da mulher no mercado de trabalho, as quais passaram a ter mais proteção legal e conquistado maior autonomia econômica. Contudo, certo é que a desigualdade de gênero ainda persiste no mercado de trabalho, sendo necessário fortalecer as instituiçõos e políticas públicas visando acabar com essa desigualdade.

Dados estatísticos mostram a desigualdade entre homens e mulheres existente dentro das empresas, seja no momento da contratação, no decorrer do contrato de trabalho ou na demissão.

Em se tratando da discriminação na dispensa em razão do gênero, outro ponto muito delicado é a questão do ônus da prova, a quem sabe provar que a dispensa foi ou não em razão do gênero? Certo é que a prova dentro do processo não pode se tornar onerosa demais a nenhuma das partes. 
Assim, é crucial entendermos todas as consequências da distribuição do ônus da prova quando se trata de suposta dispensa discriminatória em razão do gênero, bem como nos apoiarmos as diversas alternativas para a solução de casos delicados como esses.

\section{REFERÊNCIAS}

BARACAT, Eduardo Milléo. O ônus de provar a discriminação do trabalhador no empregadgo emf ace do $\S 1^{\circ}$ do art. 373 do CPC/2015. Revista Eletrônica do Tribunal Regional do Trabalho da Bahia,v. 1, p. 123-139, 2016.

BRASIL. Constituição da República Federativa do Brasil de 1988. Disponível em: <http://www.planalto.gov.br/ccivil_03/Constituicao/Constituicao.htm>. Acesso em: 15 jul. 2019.

BRASIL. Lei n. ${ }^{\circ}$ 13.467, de 13 de julho de 2017. Altera a Consolidação das Leis do Trabalho (CLT), aprovada pelo Decreto-Lei n. ${ }^{\circ} 5.452$, de $1 .^{\circ}$ de maio de 1943 , e as Leis n. ${ }^{\circ s} 6.019$, de 3 de janeiro de 1974, 8.036, de 11 de maio de 1990, e 8.212, de 24 de julho de 1991, a fim de adequar a legislação às novas relações de trabalho. Disponível em: <http://www.planalto.gov.br/ccivil_03/_Ato2015-2018/2017/Lei/L13467.htm>. Acesso em: 15 jul. 2019.

BARROS, Alice Monteiro de. Discriminação no emprego por motivo de sexo. In VIANA, Márcio Túlio; RENAULT, Luiz Otavio Linhares (Coords). Discriminação, São Paulo: LTr, 2002

Calil, Léa Elisa Silingowschi. Direito do Trabalho da Mulher, São Paulo: LTr, 2007

CANOTIlHO, José Joaquim. Direito Constitucional e Teoria da Constituição. $4^{\circ}$ ed. Coimbra: Livraria Almedina, 2000.

DENTI, Vittorio. L'inversioni dell'onere della prova: rilievi introduttivi. In: Rivista Trimestrale de Diritto e Procedura Civile, 1992

GIGLIO, Wagner D. Direito Processual do Trabalho. 16 ed. São Paulo: Saraiva, 2007

GRUBBA, Leiliane Serratine e CADEMARTORI, Luiz Henrique Urquhar. Direitos Humanos e Direitos Fundamentais: Convergência entre Joaquim Herrera Flores e Luigi Ferrajoli. Disponível em: https://portalperiodicos.unoesc.edu.br/. Acesso em: 01 ago. 2019.

GOMES, Joaquim Barbosa. Ação Afirmativa e Princípio Constitucional da Igualdade. Rio de Janeiro: Renovar, 2001.

JAKUTIS, Paulo Sérgio. O Ônus Da Prova No Processo Protetivo Do Trabalho. São Paulo: LTr, 2017,

LEITE, Marcia de Paula e SALAS, Carlos. Trabalho e desigualdades sob um novo modelo de desenvolvimento. Tempo Social, USP, v. 26, n. 1, 2014. 
LUÑO, Antonio Pérez. Dimensiones de la igualdad. 2a ed. Madri: Dykinson, 2007.

MARTINS, Sérgio Pinto. Direito Processual do Trabalho. 40 ed. São Paulo: Saraiva, 2018

MORAES, Alexandre de. Direito Constitucional. $5^{\circ}$ ed. rev. e ampl. São Paulo: Atlas, 1999.

NEVES, Marcelo. Entre Têmis e Leviatã: uma relação difícil: o Estado democrático de direito a partir e além de Luhmann e Habermas. São Paulo: Martins Fontes, 2006

PRONI, Marcelo Weishaupt e LEONE, Eugenia Troncoso. Desigualdades de gênero e raça no mercado de trabalho brasileiro. In: KREIN, José Dari et al. (Orgs.). Regulação do trabalho e instituições públicas. São Paulo: Fundação Perseu Abramo, 2013. v.2.

RAMALHO, Maria de Rosário Palma. Estudo de Direito do Trabalho. Almedina, 2003 v. 1

SCHIAVI, Mauro. Provas no Processo do Trabalho. São Paulo: LTr, 2001

SGARBIERI, Astrid Nilsson. Representações do gênero feminino na mídia impressa. Estudos Linguísticos, Campinas, v. XXXV, 2006.

SILVESTRE, Gilberto Fachetti; BORGES, Carolina Biazatti; BENEVIDES, Nauani Schades. THE APPLICATION OF THE DYNAMIC THEORY OF THE BURDEN OF PROOF IN CIVIL MATTER AFTER THE VALIDITY OF THE CODE OF CIVIL PROCEDURE OF 2015: AN ANALYSIS OF DECISIONS. Revista Juridica, [S.1.], v. 1, n. 58, p. 137 - 158, abr. 2020. ISSN 2316-753X. Disponível em: <http://revista.unicuritiba.edu.br/index.php/RevJur/article/view/3827/371372168>. Acesso em: 21 abr. 2020. doi:http://dx.doi.org/10.21902/revistajur.2316-753X.v1i58.3827.

SOUZA SANTOS, Boaventura de. Reconhecer para libertar: os caminhos do cosmopolitanismo multicultura. Rio de Janeiro: Civilização Brasileira, 2003

STEIL, Andrea Valéria. Organizações, gênero e posição hierárquica - compreendendo o fenômeno do teto de vidro. Revista de Administração, v. 32, n. 3, 1997

VIANA, Márcio Túlio e RENAULT, Luiz Otavio Linhares (Coords). Discriminação, São Paulo: LTr, 2002 